\title{
Sleep disturbances and health problems:
} sleep matters

In this issue of the Journal, two papers highlight the importance of sleep. The first reiterates the role of obstructive sleep apnoea in patients with hypertension and how continuous positive airway pressure (CPAP) therapy can improve blood pressure. ${ }^{1}$ The second, a qualitative study with patients and clinicians, restates the need for practitioners to be more aware of patients' concerns and the impact of the sleep problem on their lives. ${ }^{2}$

Sleep has been associated with health problems for a long time. Classically, sleep disturbances, particularly early morning awakening and an inability to get off to sleep, have been associated with anxiety and depression. The consequences of inadequate sleep have been associated with lack of concentration, daytime sleepiness, and impaired performance. Transport authorities have long recognised this through restrictions on heavy vehicle drivers and airline pilots. Closer to home, European Working Time Directives have restricted the amount of on-call allowed, leading to a radical shift in NHS work patterns.

However, there can be confusion as to what constitutes a sleep problem. One approach is to consider two entities: first, sleep-disordered breathing including obstructive sleep apnoea, hyperventilation syndrome, upper airways resistance syndrome, and night-time Cheyne-Stokes breathing; and secondly, sleep disruption per se, not associated with a breathing disorder. As GPs, we seldom receive training to recognise different forms of sleep disorder or to identify interactions with other conditions. Validated screening tools remain the domain of sleep specialists. For as long as undifferentiated sleep disorders are inappropriately labelled as 'insomnia', we are likely to remain oblivious to useful interventions which might ameliorate associated health problems.
Obstructive sleep apnoea is associated with many health problems. It is characterised by recurrent episodes of cessation of respiratory airflow during sleep caused by the collapse of the upper airway at the pharyngeal level. ${ }^{3,4}$ It can cause excessive daytime drowsiness, most probably related to fragmentation of sleep by recurrent arousals, the loss of deeper levels of sleep, and the effect of reduced oxygenation on cerebral function. ${ }^{3}$

In addition to daytime drowsiness, sleep-disordered breathing is associated with negative metabolic effects, such as on cardiovascular physiology, and has been associated with cardiovascular disease. The effect is likened as 'modest to moderate' on the manifestations of cardiovascular disease including angina, myocardial infarction, heart failure, and stroke. $^{5}$ In patients with heart failure, quality of life is compromised by sleeprelated disorders. ${ }^{6}$ Various mechanisms have been mooted for the observed association between sleep disorders and cardiac events, especially involving psychological depression. ${ }^{7}$ First, an as yet unknown atherogenic pathway in which depression leads to the development of atherosceleric plaques. ${ }^{8}$ Secondly, by a similar pathway, depression and/or insomnia may accelerate pre-existing atherosclerosis and the risk of myocardial infarction. ${ }^{9}$ At the same time, and this is the unresolved cause-effect conundrum in sleep and health disorders, underlying coronary heart disease may actually be the cause of the depressive symptoms and not vice versa. ${ }^{7}$

There are also recognised associations between sleep disturbance and diabetes. Sleep exerts a modulating effect on glucose metabolism and the effects of sleep disturbance have been associated with diabetes as well as obesity. Experimentally-induced recurrent partial sleep restriction in healthy young adults has been associated with marked alterations in glucose metabolism, including decreased glucose tolerance and insulin sensitivity. Thus, chronic sleep loss, whether behavioural or sleep disorder related, may represent a risk factor for weight gain, insulin resistance, and type 2 diabetes. ${ }^{10}$ Equally, sleep disturbances themselves may result from diabetes through mechanisms related to central control of respiration. This high prevalence of sleep-disturbed breathing may be a treatable risk factor for cardiovascular disease in people with diabetes. ${ }^{11}$

While depression and sleep disorders have been classically linked, metabolic factors are also important. Patients with excessive daytime sleepiness need to be assessed for depression as well as for obesity, diabetes, and cardiovascular problems, whether or not they appear to have a sleep-disturbed breathing problem.

On a speculative basis, sleep problems may well be associated with a much wider range of problems. We know relatively little about the body's physiological rhythms and their impact on wellbeing and health within the context of specific diseases. Gastroesophageal reflux disease (GORD) (a highly prevalent disorder within the community with a frequency of $25-50 \%{ }^{12}$ ) has been highlighted in terms of its night-time occurrence. Night-time reflux disease may be more associated with complications than daytime reflux, including an increased risk of developing oesophagitis and respiratory complications. $^{12} \quad$ A bidirectional relationship between GORD and sleep has been described whereby night-time reflux leads to sleep deprivation and sleep deprivation can exacerbate GORD by enhancing perception of intra- 
oesophageal stimuli. ${ }^{13}$ Equally, while the relationship between anxiety and depression has been studied across a wide range of functional problems such as irritable bowel syndrome (IBS) and fibromyalgia, there are relatively little data to link these with sleep disturbances. Nonetheless, research has revealed an association between IBS and sleep disturbance ${ }^{14,15}$ and an increased rate of sleep complaints among IBS sufferers. ${ }^{16}$ One theory is that there is disordered autonomic functioning in IBS sufferers during rapid eye movement sleep. ${ }^{17}$ Similarly, studies associate fibromyalgia with disturbed sleep. ${ }^{18}$ There is also evidence associating osteoarthritis pain with sleep disorder possibly through a contribution to hyperalgesia and impaired endogenous pain modulation. ${ }^{19}$ Sleep disturbances may be a common factor in ageing and long-term disorders and in functional problems.

The challenge lies in learning more about sleep problems and associations with other health problems and how we might usefully intervene for better outcomes. The starting point is to take sleep disturbances more seriously and to assess how they impact on individual patients. Modifying outcomes through better management of sleep problems is likely to be rewarding in many patients, especially those with obstructive sleep apnoea. The importance of sleep is increasingly recognised in clinical research - associations are likely to be more important than previously anticipated.

\section{A Pali S Hungin,}

Dean of Medicine and Professor of Primary Care and General Practice, School of Medicine and Health, Durham University, Stockton on Tees.

\section{Helen Close,}

Research Fellow, School of Medicine and Health, Durham University, Stockton on Tees.

\section{Provenance}

Commissioned; not peer reviewed.

\section{REFERENCES}

1. Di Guardo A, Profeta G, Crisafulli C, et al. Obstructive sleep apnoea in patients with obesity and hypertension. Br J Gen Pract 2010; 60: 325-328.

2. Dyas JV, Apekey TA, Tilling M, et al. Patients and clinicians experiences of consultations in primary care for sleep problems and insomnia: a focus group study. Br J Gen Pract 2010; 10.3399/bjgp10X484183.

3. Phillipson EA. Sleep apnoea - a major public health problem. N Engl J Med 1993; 328(17): 1271-1273.

4. Hudgel DW. The role of upper airway anatomy and physiology in obstructive sleep apnea. Clin Chest Med 1992; 13(3): 383-398.

5. Shahar E, Whitney CW, Redline S, et al. Sleepdisordered breathing and cardiovascular disease. Am I Respir Crit Care Med 2001; 163: 19-25.

6. Skobel E, Norra C, Sinha A, et al. Impact of sleeprelated breathing disorders on health-related quality of life in patients with chronic heart failure. Eur J Heart Fail 2005; 7(4): 505-511.

7. Nicholson A, Fuhrer R, Marmot M. Psychological distress as a predictor of CHD events in men: the effect of persistence and components of risk. Pyschosom Med 2005; 67: 522-530.

8. Ford DE, Mead LA, Chang PP, et al. Depression is a risk factor for coronary heart disease in men. Arch Intern Med 1998; 158: 1422-1426.

9. Carney RM, Freedland KE. Depression, mortality, and medical morbidity in patients with coronary heart disease. Biol Psychiatry 2003; 54: 241-247.

10. Spiegel K, Knutson K, Leproult R, et al. Sleep loss: a novel risk factor for insulin resistance and type 2 diabetes. J Appl Physiol 2005; 99(5): 2008-2019.

11. Resnick HE, Redline S, Shahar E, et al. Diabetes and sleep disturbances: findings from the Sleep Heart Health Study. Diabetes Care 2003; 26(3): 702-709.
12. Orr WC. Review article: sleep-related gastrooesophageal reflux as a distinct clinical entity. Aliment Pharmacol Ther 2010; 31(1): 47-56.

13. Fass R. The relationship between gastroesophageal reflux disease and sleep. Curr Gastroenterol Rep 2009; 11(3): 202-208

14. Heitkemper M, Jarrett M, Burr R, et al. Subjective and objective sleep indices in women with irritable bowel syndrome. Neurogastroenterol Motil 2005; 17(4): 523-530

15. Vege SS, Locke GR III, Weaver AL, et al. Functional gastrointestinal disorders among people with sleep disturbances: a population-based study. Mayo Clin Proc 2004; 79(12): 1501-1506.

16. Orr WC, Heading R, Johnson LF, Kryger M. Review article: sleep and its relationship to gastrooesophageal reflux. Aliment Pharmacol Ther 2004; 20 Suppl 9: 39-46.

17. Orr WC, Chen CL. Sleep and the gastrointestinal tract. Neurol Clin 2005; 23(4): 1007-1024.

18. Martin S, Chandran A, Zografos L, Zlateva G. Evaluation of the impact of fibromyalgia on patients sleep and the content validity of two sleep scales. Health Qual Life Outcomes 2009; 7: 64.

19. Smith MT, Quartana PJ, Okonkwo RM, Nasir A. Mechanisms by which sleep disturbance contributes to osteoarthritis pain: a conceptual model. Curr Pain Headache Rep 2009; 13(6): 447-454.

DOI: 10.3399/bjgp10X484147

\section{ADDRESS FOR CORRESPONDENCE}

\section{A Pali S Hungin}

Centre for Integrated Health Care Research, The Wolfson Research Institute, University of Durham, Queen's Campus, Stockton on Tees, TS16 9BT. Email: a.p.s.hungin@durham.ac.uk 